\title{
Measurement of knee articulation laxity by videofluoroscopy image analysis: CINARTRO
}

\author{
Franco Simini ${ }^{1 *}$, Dario Santos ${ }^{1,2,3}$, José Artigas ${ }^{1}$, Verónica Gigirey ${ }^{4}$, Luis Dibarboure ${ }^{4}$ and Luis Francescoli ${ }^{5}$ \\ *Correspondence: simini@fing.edu.uy \\ CrossMark \\ $\leftarrow$ Click for updates

\begin{abstract}
'Núcleo de Ingeniería Biomédica, Facultades de Medicina e Ingeniería, Universidad de la República - Montevideo, Uruguay. 2Departamento de Rehabilitación - Biomecánica Clínica, Hospital de Clínicas, Montevideo, Uruguay.

${ }^{3}$ Escuela Universitaria de Tecnología Médica, Universidad de la República, Montevideo, Uruguay.

${ }^{4}$ Departamento de Imagenología Clínica, Hospital de Clínicas, Montevideo Uruguay.

${ }^{5}$ Clínica de Ortopedia y Traumatología, Facultad de Medicina, Montevideo Uruguay.
\end{abstract}

\begin{abstract}
Several methods are used to evaluate knee articulation during movement, such as the Tibio Femoral Contact Point migration or the Instantaneous Centre of Rotation displacement and even the Moment Arm variations during extension. Such evaluation is important in case of Anterior Cruciate Ligament reconstruction or Total Knee Replacement, but unfortunately, it is only available in research settings. We have devised a novel clinical methodology based on serial images of knee movement videofluoroscopy, which are interactively analysed to allow automatic determination of kinematics parameters. The method, called CINARTRO, compares values with the contralateral knee and produces a standard Clinical Document Architecture file ready for Electronic Medical Record systems. To correct the "pin cushion" effect of X ray intensifiers, a $10 \mathrm{~mm}$ apart lead spheres phantom was developed. To validate the interactive selection of anatomical points, cadaver limbs were marked with lead markers and compared with points marked on the blind image. Anterior Cruciate Ligament (injured and reconstructed) and contralateral Moment Arms averages of $53 \mathrm{~mm}, 39 \mathrm{~mm}$ and $43 \mathrm{~mm}$ respectively were found. Similarly the Total Knee Replacement patient`s Moment Arm was reduced to 33mm. These findings justify the use of our methodology to help clinicians during rehabilitation follow-up.
\end{abstract}

Keywords: Knee Kinematics, Tibio Femoral Contact Point, Quadriceps Moment Arm, Videofluoroscopy, CINARTRO

\section{Introduction}

The knee articulation (KA) is a very complex structure of the human body, with several functions such as ensuring static stability during full extension of the leg, shortening of the leg to allow movement and adaptation to ground irregularities during gait and running [1]. Until recently, clinical evaluation of movement is the result of subjective appraisal, highly dependent upon the observer. A few quantitative and therefore objective methods are available in the literature, all circumscribed within research settings. One method is the determination of the Tibio Femoral Contact Point (TFCP) and its migration over the tibial plateau during flexo/extension $[2,3]$.

The knee is subject to continuous movements and exercises in everyday life. After a serious lesion such as the rupture of the Anterior Cruciate Ligament (ACL) the knee joint kinematics are altered [1]. The yearly incidence of injured $A C L$ is one every 3000 persons, which implies an ample field of clinical work to be performed. In the economy, it accounts for over a billion dollars in surgical and rehabilitation costs only in the USA [4].
Total Knee Replacement (TKR) is an effective way to treat knee arthropathies, for which it is considered the definitive treatment for symptomatic end-stage osteoarthritis of the knee [5]. TKR is a successful treatment for most pain and dysfunction conditions in patients $[6,7]$. Postoperatively, functional instabilities may develop which require careful and evidence-based rehabilitation. One of the most common ways to check the state of a re-constructed knee is the Lachman test [2]. This evaluation depends greatly upon the perception and experience of the physician or rehab technician. An objective, quantitative measurement is needed and no such instrument exist to help the clinicians. To address the lack of objective methods available for routine clinical settings, we set ourselves the goal of designing a simple way with the simplest possible instrumentation and software. The determination of knee arthrokynematics could be used as an objective method to evaluate $A C L$ reconstruction [3,4]. As an objective measurement, TFCP migration data, for instance, can help to put in place rehabilitation strategies and are suitable to monitor them, as well as to give feedback 
to the surgeon and Physical Rehabilitation Medicine staff. The methodology and the clinical instrument to be used for follow-up will be based on our prior medical device development experience $[5,6]$ and the best available biomechanics research findings.

We have developed a way to enhance and supplement the subjective test with quantitative methods [7-9]. The aim of CINARTRO [7] (such is the name of our instrument, named as the contraction of "CINE" which stands for "KINEMATICS" and ARTRO for "ARTHRO" meaning "joint") is the collection of data and images to be processed into numerical results to help determine the condition of the patient after an ACL surgery [8]. The set of videofluoroscopy (VFC) images is the source of input data to the software, which interacts with the user to produce a relevant clinical report for the patient's medical record. After preliminary evidence of knee dynamics evaluations [10], and developing a routine for VFC capture of the movement [11], we describe in the present paper the proof of concept of CINARTRO including calibration with phantom and cadaveric limb, as well as pave the way for the measurement of the degree of knee tightness or laxity.

\section{Specifications of the method}

\section{Use cases of the instrument to be designed}

- After an ACL lesion and either a surgical reconstruction or rehabilitation, the main concern of the surgeon or physiotherapist is to count on reliable and objective elements on which to base decisions during follow-up $[12,13]$.

- The instrument to be designed will add quantitative input to the traditional clinical approach of gait observation and tests such as the one described by Lachman using the arthrometer, (e.g.: KT-1000 y KT- 2000) [14].

- In addition to the usual static clinical imaging studies such as $\mathrm{X}$ rays, $\mathrm{CT}$ scans and $\mathrm{MR}$, which show anatomical structures in great detail, the user needs to evaluate the dynamic aspects, i.e., the essence of knee joint function [5]. CINARTRO has to analyse moving images to produce kinematics parameters of clinical value [8].

- The instrument we design should document knee kinematics characteristics in the Electronic Clinical Record.

- Since CINARTRO uses X-ray equipment of different geometries, it must compensate distortion for each one of them.

- CINARTRO version 1 is specified to study knees in open chain [15], while later versions capture and analyze the body-loaded knee joint movement, walking up and down standard steps [16].

\section{Specifications of CINARTRO software}

The Software we develop should be able to read DICOM images produced by the $\mathrm{X}$-ray equipment, either the $\mathrm{C}$-arm or other real time X-ray equipment. Based on this information, it must produce clinically relevant evidence according to the following specifications:

- Display of VFC series of images
Interactive point definition to determine the extremities of the Tibial Plateau, the Femoral Condyle, the Patella Extremity and the Tuberosity Notch. Figure 3 shows an example of determination of these points.

- Automatic spline determination of the Femoral Condyle from the three points spotted by the user.

- Automatic calculation of the TFCP as the midpoint of the Tibial Plateau to Femoral Condyle distance, in every image, following the Baltzopoulos method [3,17].

- Automatic calculation of the Moment Arm as the distance between the "Patella Notch to Tibial Tuberosity" segment and the centre of rotation. As a proxy for the moving instantaneous centre of rotation, we have used the TFCP $[18,19]$.

- When displaying the subsequent image, our software [20] suggests all the fiducial points in plausible positions, determined from previous image points extrapolated along the extending tibia. In open chain movements, the femur points suggested by the software are always in the same position as in the previous image, since the femur does not move, the patient being seated.

- Once the operator processes the series of VFC images, the software calculates the TFCP migration as a percentage of the Tibial Plateau dimension.

- The software must generate a clinical report in two formats: PDF (Portable Document Format) and CDA (Clinical Document Architecture) for Electronic Clinical Record interoperability.

\section{Design of CINARTRO}

\section{Building block of the instrument CINARTRO}

To record a moving joint we chose a sequence of VFC images at a rate of 15 images per second during a two-second extension movement. This method has the advantage over conventional Roentgen moving film analysis (once known as RSA - Roentgen Stereo photogrammetry Analysis) in the much lower ionizing radiation delivered to the patient. The disadvantage of using VFC is the optical distortion inflicted to the image by the curvature of the image intensifier [3]. Using clinical VFC available for angiocardiographic or gastroscopic dynamic exploration, the overall dose delivered was 250 microGy $(\mathrm{J} / \mathrm{Kg})$ absorbed for every two seconds movement. To obtain VFC series we have used a variety of X-ray equipment provided they had serial imaging capacity. In Figure 1 we use a $C$ arm and in Figure 2 a gastric dynamic imaging system. The images are recorded in DICOM format, with single images ready for further processing in Bit Map Picture (BMP). We designed an original software to process the series of images, which consists of an interactive application to allow the user to select fiducial points on the images. The CINARTRO software shows on the image the homothetic places coming from the previous one to help the operator by suggesting points to be either confirmed or modified. The eleven anatomical points prompted by the software are shown in the left 


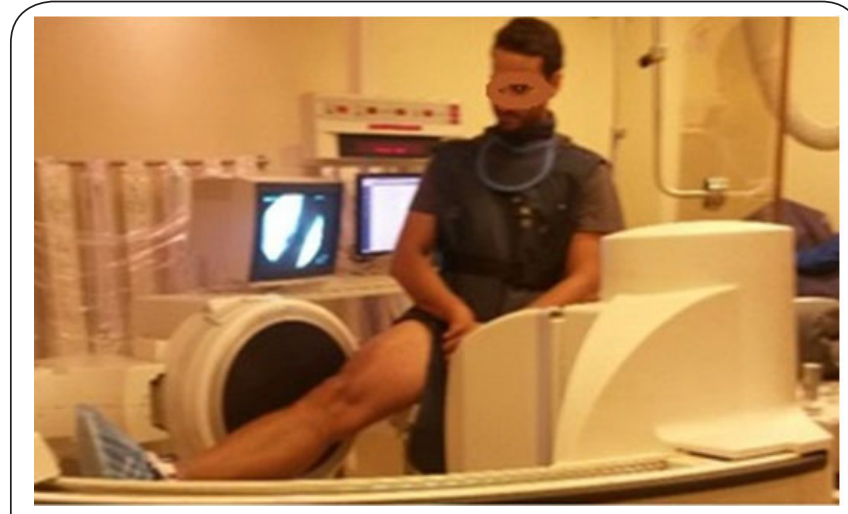

Figure 1. C-arm used to obtain videofluoroscopic (VFC) images of a moving knee joint. Note the subject is seated in proximity of the image intensifier with a hanging leg. When ordered, the patient extends the leg while obtaining VFC images.

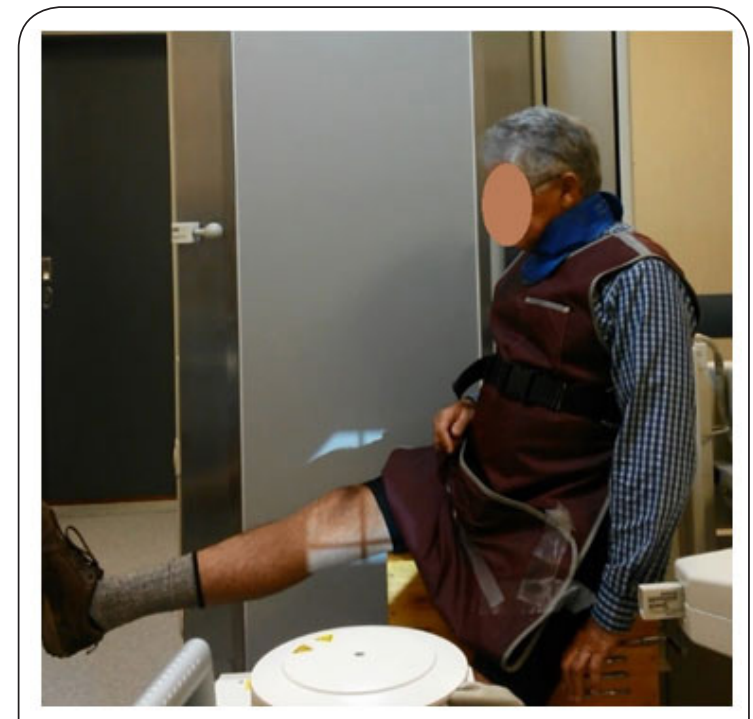

Figure 2. Patient with Total Knee Replacement (TKR) during CINARTRO Videofluoroscopic procedure to evaluate dynamic functional knee parameter in open chain, i.e. under no load. X-ray equipment used for dynamic gastric evaluation is used here.

column of Figure 4. The first five points include three points on the Femoral Condyle and the two Tibial Plateau extremities. The second group includes two pairs of long bone surface points to determine the flexion angle. Finally, the last group comprises the Patella Extremity and the Anterior Tuberosity Notch, to allow the software to define the quadriceps ligament direction, and thus the Moment Arm.

\section{Image quality control to reduce pin cushion effect} In order to correct the pin cushion distortion effect, we have designed a plastic device [20-22] with lead spheres separated by $10 \mathrm{~mm}$ in a two dimensional regular pattern (Figure 3). We

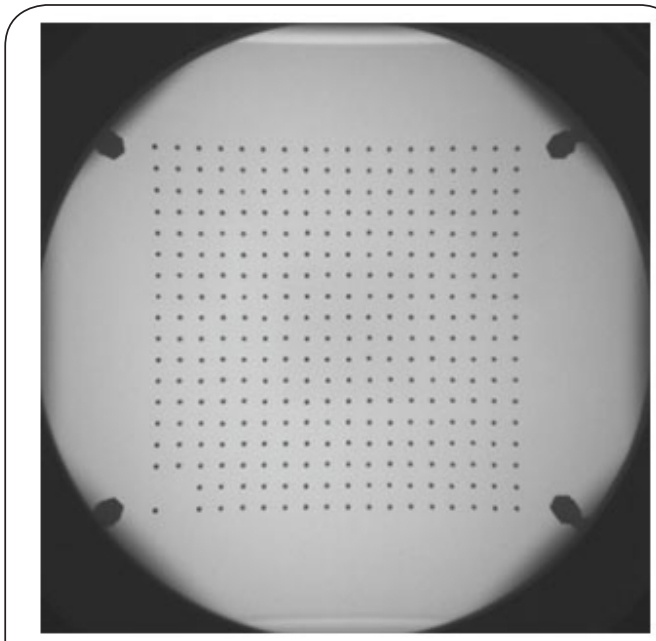

Figure 3. Phantom specially designed and built to obtain an image of the lead sphere pattern, distorted as a result of intensifier/source geometry (Pincushion effect). Point coordinates are correcated based on the transformation deduced from the phantom. Spheres are $1 \mathrm{~mm}$ in diameter and spaced $10 \mathrm{~mm}$ from each other. This image was obtained with Angiostar Plus, SIEMENS.

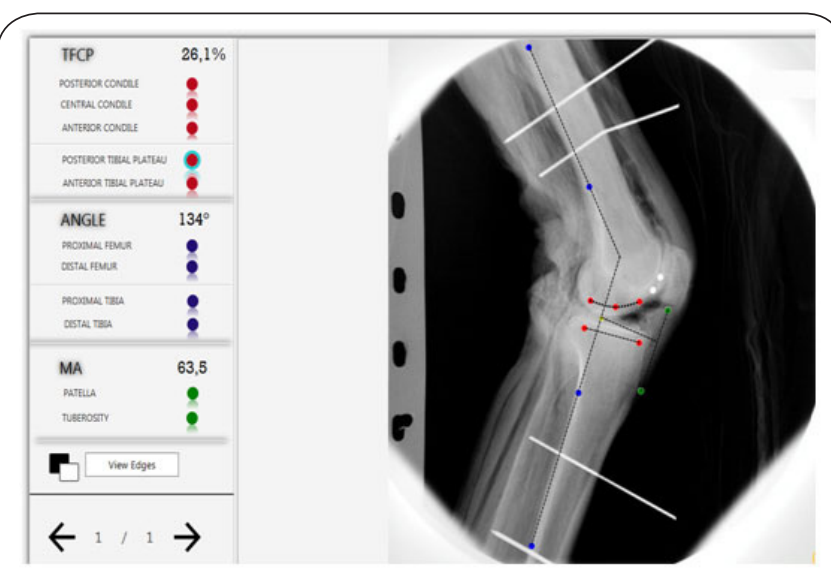

Figure 4. Screen of CINARTRO software. On the left side, the fiducial points are displayed and the operator clicks on one of them before marking a spot in the image on the right. As the points are marked, the software displays in bold characters on the left side of the screen, the angle of the Femoral-Tibial extension and the Moment Arm (MA) once the Tibio Femoral Contact Point (TFCP) is automatically determined and shown on every image.

called the device "Phantom" and it was placed in the sagittal plane the patients would be located subsequently. Due to the relative intensifier/source geometry, the $\mathrm{X}$-ray image taken of the Phantom pattern appears distorted. By matching the theoretical position of every lead sphere with their real position, our software $[3,20]$ is able to correct the operatordefined fiducial points. We have put in practice the method published by Baltzopoulos [3] which minimizes a global error 
function with linear algebra methods. By doing so, we obtain a set of parameters for the transformation of the VFC point coordinates into "corrected" points. The same transformation derived from the Phantom image is later applied to all operator selected points on patient knee joint images. The image analysis is therefore free from major geometrical distortion.

The error in TFCP migration was found to be less than $2 \%$ of the Tibial Plateau dimension in case the pincushion effect was not corrected [23]. A TFCP measurement of $40 \%$ of Tibial Plateau extension, with an uncertainty of $2 \%$ can be made better with pincushion distortion correction. After correction, the error has no practical relevance in direct and derived measurements.

\section{Results Using CINARTRO}

\section{Validation of operator point marking}

In order to verify that the operator marks the anatomical points correctly, we surgically prepared a cadaveric lower limb with lead spheres in the exact places of the Tibial Plateau extremities and along the Femoral Condyle. Similarly, we also put spheres at the lower end of the Patella and at the Tuberosity Notch.

In addition, the cadaveric limb was marked with steel rods to measure the flexion angle (Figure 4), as a check for the angle measured by CINARTRO software when processing the images.

Comparing cadaveric marked points with operator selection on blind images, the mean difference between series is 5\% for the TFCP migration [24]. Similarly, the MA values obtained differ by a mean value of 3\% [24], (Figure 5).

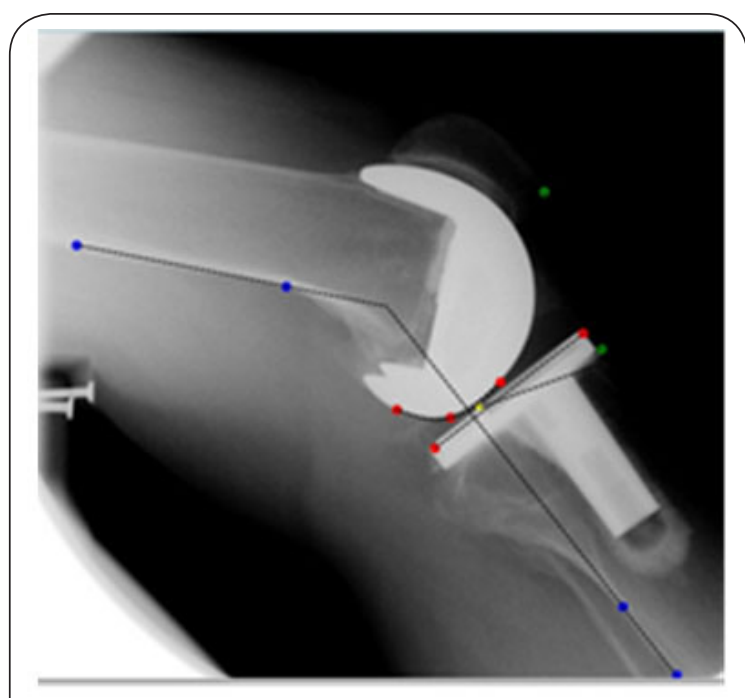

Figure 5. Anatomical points marked by the user with CINARTRO on a Total Knee Replacement (TKR) image of patient of Figure 2. One of a series of VFC images taken during "open chain" movement of a sitting patient. The line between patella and anterior tuberosity identifies the quadriceps ligament (green points to the right). Note the Tibial Plateau highlighted by 2 points and the Femur Condyle contour by 3 points. The yellow point is calculated by CINARTRO as a proxy of the instantaneous center of rotation (TFCP).
CINARTRO to evaluate ACL reconstructed patients We used CINARTRO to evaluate $A C L$ reconstruction of six subjects, after securing Ethics Committee project approval. Table 1 shows the results in terms of percentage of the Tibial Plateau to normalize dimensions across patients. The MA is increased when the $A C L$ is injured, returning to close to normal after reconstruction.

Table 1. Quadriceps moment arm of 6 patients.

\begin{tabular}{lllll}
\hline Patient Condition & \multicolumn{4}{c}{ Position of leg } \\
\cline { 2 - 5 } & $\mathbf{1 3 5}^{\mathbf{0}}$ & $\mathbf{1 5 0}^{\circ}$ & $\mathbf{1 6 5}^{\mathbf{0}}$ & $\mathbf{1 8 0}^{\mathbf{0}}$ \\
& Hanging leg & & & Fully extended \\
\hline Healthy (mm) & $39 \pm 3$ & $45 \pm 5$ & $43 \pm 5$ & $44 \pm 3$ \\
ACL Injured (mm) & $47 \pm 5$ & $51 \pm 7$ & $62 \pm 5$ & $53 \pm 4$ \\
ACL Reconstructed & $38 \pm 3$ & $41 \pm 4$ & $40 \pm 2$ & $37 \pm 2$ \\
\hline
\end{tabular}

CINARTRO produces a clinical document, which includes a graphic representation of the TFCP migration and the MA as the extension progresses. Figure 6 is an example of such representation where the migration of the TFCP is shown to span from $42 \%$ to $60 \%$ of the Tibial Plateau length.

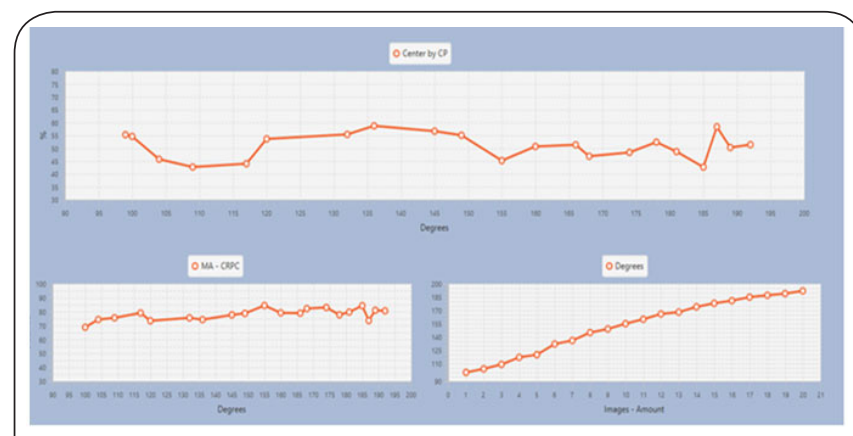

Figure 6. Clinical results for the Patient Report. The upper graph shows the Tibio Femoral Contact Point (TFCP) migration as a percentage of the Tibial Plateau, during active extension from $90^{\circ}$ to $180^{\circ}$ (full extension). The lower left is the Moment Arm length, which varies from roughly 60 to 80 $\mathrm{mm}$. The lower right is a check of the limb angle $\left(90^{\circ}\right.$ to $180^{\circ}$ full extension) and image number (1 to 30 ) in abscissa.

\section{CINARTRO to evaluate total knee replacement}

We used CINARTRO to evaluate a Total Knee Replacement (TKR) patient (Figure 2), after obtaining his informed consent and Ethics Committee approval. Table 2 shows the results of the center of rotation proxy migration in terms of percentage of the Tibial Plateau compared to normal patients. The MA is also shown in Table 2 with the same normal reference values.

\section{Discussion}

When the $A C L$ is repaired, the rehabilitation process aims at strengthening muscular action and neuromuscular control, in order to preserve as much as possible the original functions present prior to the lesion. In particular, the initial training 
Simini et al. Medical Imaging and Radiology 2017,

http://www.hoajonline.com/journals/pdf/2054-1945-5-4.pdf

doi: $10.7243 / 2054-1945-5-4$

Table 2. Total knee replacement moment arm.

\begin{tabular}{|c|c|c|c|c|c|}
\hline & \multirow{2}{*}{$\begin{array}{l}\text { Patient } \\
\text { Condition }\end{array}$} & \multicolumn{4}{|c|}{ Position of leg } \\
\hline & & $\begin{array}{l}135^{\circ} \\
\text { Hanging leg }\end{array}$ & $150^{\circ}$ & $165^{\circ}$ & $\begin{array}{l}180^{\circ} \\
\text { Fully extended }\end{array}$ \\
\hline \multirow{2}{*}{$\begin{array}{l}{ }^{* *} \text { Moment } \\
\text { Arm }(\mathrm{mm})\end{array}$} & Normal & 39 & 45 & 43 & 44 \\
\hline & TKR & 35 & 35 & 32 & 30 \\
\hline Reduction & -- & $10 \%$ & $22 \%$ & $25 \%$ & $32 \%$ \\
\hline
\end{tabular}

phases are critical in strengthening quadriceps without damaging the reconstructed $A C L$ [13]. When the $A C L$ is injured, the quadriceps force is reduced [8]. We have shown here that the MA is slightly increased when ACL is injured (Table 1), which can be considered a compensation of the reduction in quadriceps strength, trying to keep the Moment constant (remember that Moment is the product of Force by MA).

The increase of MA secondary to ACL injury is shown in the same Table 1 to be reduced after ACL reconstruction, in an attempt to recover normal values. An average over the four values of healthy knee (across extension angles $135^{\circ}$, $\left.150^{\circ}, 165^{\circ} \& 180^{\circ}\right)$ is $M A=43 \mathrm{~mm}$, quite similar to established findings [25]. When injured, the mean $M A=53 \mathrm{~mm}$. After reconstruction, the surgeon contributes with a resulting mean $M A=39 \mathrm{~mm}$. This can be interpreted as a tighter knee joint to be taken over by rehabilitation. Quadriceps strength must be increased as a measure to counteract the surgical reduction of MA. A non-repaired $A C L$ is probably compatible with a weakened quadriceps, but a repaired ACL (with lower MA) must be moved by a powerful quadriceps.

In case of the TKR patient, the MA (33 mm) is lower than the normal mean MA (from Table 1 mean $M A=43 \mathrm{~mm}$ ). As in the $A C L$ reconstructed cases, the TKR patient also requires professional rehabilitation.

Clinical practice of $\mathrm{ACL}$ reconstruction follow-up has demanded for many years a practical instrument to benefit from research in joint kinematics [26]. On one side research explained the dynamics of the consequences of $A C L$ rupture [12] and the partial reconstruction obtained with different surgical techniques. This explanation remained within the realm of academic work, while clinicians had no other way to record the evolution of a repaired ACL but static images and simple clinical procedure such as the KT1000 or Lachman test. By developing CINARTRO, we are suggested an objective procedure to record the result of $A C L$ reconstructive surgery immediately after inflammation lowers, and later at intervals during physiotherapy and rehabilitation [8].

The X-ray system used for the present preliminary proof of concept of CINARTRO is available but cumbersome to use and expensive. We are working towards the design of a dedicated compact X-ray device, probably derived from veterinary equipment [20], which will allow us to design a simple, portable CINARTRO for routine clinical practice.

Future work will address the measurement of forces involved in the intact/torn/reconstructed $\mathrm{ACL}$ settings. By doing so, we will be able to further explore the hypothesis of quadriceps strength reduction with injured ACL or TKR. Consequently, rehabilitation will be asked to restore higher performance muscles to deal with reconstructed $A C L$ and therefore with often shortened MA.

\section{Competing interests}

The authors declare that they have no competing interests.

Authors' contributions

\begin{tabular}{|l|c|c|c|c|c|c|}
\hline Authors' contributions & FS & DS & JA & VG & LD & LF \\
\hline Research concept and design & $\checkmark$ & $\checkmark$ & -- & -- & -- & -- \\
\hline Collection and/or assembly of data & -- & $\checkmark$ & $\checkmark$ & -- & -- & -- \\
\hline Data analysis and interpretation & $\checkmark$ & $\checkmark$ & $\checkmark$ & $\checkmark$ & $\checkmark$ & $\checkmark$ \\
\hline Writing the article & $\checkmark$ & $\checkmark$ & $\checkmark$ & -- & -- & -- \\
\hline Critical revision of the article & $\checkmark$ & $\checkmark$ & $\checkmark$ & $\checkmark$ & $\checkmark$ & $\checkmark$ \\
\hline Final approval of article & $\checkmark$ & $\checkmark$ & $\checkmark$ & $\checkmark$ & $\checkmark$ & $\checkmark$ \\
\hline Statistical analysis & $\checkmark$ & $\checkmark$ & -- & -- & -- & - \\
\hline
\end{tabular}

\section{Acknowledgments}

The authors thank Dr. Teresa Camarot, Director of the Rehabilitation and Physical Medicine Department. The authors also thank Dr. Eduardo Olivera for active cooperation from the Anatomy Department, and Prof. Victor Ezquerra of the Imaging Technical Department. The authors finally thank Ignacio Ferrer, Engineering Student as well as Andrés Rey for contributions in procedures and programming tasks. Mrs. Susana Martìnez is acknowledged for excellent administrative support.

Publication history

Senior Editor: Domenico Rubello, Santa Maria della Misericordia Hospital, Italy.

Received: 21-Jul-2017 Final Revised: 30-Aug-2017

Accepted: 04-Sep-2017 Published: 15-Sep-2017

\section{References}

1. Benjaminse A, Gokeler A and van der Schans CP. Clinical diagnosis of an anterior cruciate ligament rupture: a meta-analysis. J Orthop Sports Phys Ther. 2006; 36:267-88. | Article | PubMed

2. You BM, Siy P, Anderst $W$ and Tashman S. In vivo measurement of 3-D skeletal kinematics from sequences of biplane radiographs: application to knee kinematics. IEEE Trans Med Imaging. 2001; 20:514-25. | Article I PubMed

3. Baltzopoulos V. A videofluoroscopy method for optical distortion correction and measurement of knee-joint kinematics. Clin Biomech (Bristol, Avon). 1995; 10:85-92. | Article | PubMed

4. R. Nandra, G. S. Matharu, K. Porter, T. Ashraf and I. Greaves. A review of 
Simini et al. Medical Imaging and Radiology 2017,

anterior cruciate ligament injuries and reconstructive techniques. Part 2 : Treatment. Trauma. 2013; 15:116-127.

5. J. Insall and N. Scott. Insall \& Scott surgery of the knee. 4th ed. 2005.

6. B. J. Manasteri. Pictorial Essay Total Knee Arthroplasty : Postoperative Radiologic Findings. 1995; 899-904.

7. F. Simini and D. Santos. Anterior Cruciate Ligament reconstruction follow-up instrumentation based on Centre of Rotation videofluoroscopy determination: Development of an original equipment, CINARTRO, and first clinical use. In Conference Record - IEEE Instrumentation and Measurement Technology Conference. 2014; 923926. | Article

8. D. Santos, F. Massa and F. Simini. Evaluation of anterior cruciate ligament reconstructed patients should include both self-evaluation and anteroposterior joint movement estimation? Phys. Ther. Rehabil. 2015; 2:3. | Article

9. F. Simini. Technology Transfer of Biomedical Equipment: from Bedside to Academia and to Industry to Meet Clinical Needs as Detected by Research. In IEEE Tutorial presented at I2MTC, Pisa. 2015.

10. F. Simini, D. Santos, J. Artigas, V. Gigirey, L. Dibarboure and L. Francescoli. Measurement of Knee Articulation Looseness by Videofluoroscopy Image Analysis : CINARTRO. In IEEE International Instrumentation and Measurement Technology Conference (I2MTC). 2017; 939-942. I Article

11. V. Ezquerra, D. Santos, M. Rodriguez, W. Olivera, V. Gigirey and F. Simini. Método de fluoroscopía de la rodilla en movimiento para la evaluación de la cinemática articular usando el instrumento CINARTRO," In XVIII Congreso Chileno de Tecnología Médica. 2016.

12. Micheo W, Hernandez $L$ and Seda C. Evaluation, management, rehabilitation, and prevention of anterior cruciate ligament injury: current concepts. PM R. 2010; 2:935-44. | Article | PubMed

13. D. Santos and G. Fabrica. Directrices Biomecánicas para el Entrenamiento Isométrico de Cuadriceps durante la Rehabilitación del Ligamento Cruzado Anterior. Rev. Iberoam. Fisioter. y Kinesiol. 2002; 5:101-108.

14. Prins $M$. The Lachman test is the most sensitive and the pivot shift the most specific test for the diagnosis of ACL rupture. Aust J Physiother. 2006; 52:66. | Article | PubMed

15. McGinty G, Irrgang JJ and Pezzullo D. Biomechanical considerations for rehabilitation of the knee. Clin Biomech (Bristol, Avon). 2000; 15:160-6. | Article | PubMed

16. D. Santos, F. Simini, L. Francescoli, F. Massa, A. Barquet and T. Camarot. Beyond traditional clinical evaluation of knee articulation movement to physiological assesment of dynamic ACL funtion during extension. In XIII International Symposium on 3D Analysis of Human Movement. École Polytechnique Fédérale de Lausanne; Switzerland. 2014; 62-65.

17. Tsaopoulos DE, Baltzopoulos $V$ and Maganaris $\mathrm{CN}$. Human patellar tendon moment arm length: measurement considerations and clinical implications for joint loading assessment. Clin Biomech (Bristol, Avon). 2006; 21:657-67. | Article | PubMed

18. Kellis $E$ and Baltzopoulos V. In vivo determination of the patella tendon and hamstrings moment arms in adult males using videofluoroscopy during submaximal knee extension and flexion. Clin Biomech (Bristol, Avon). 1999; 14:118-24. | Article | PubMed

19. D. Santos, W. Olivera, M. Rodriguez, P. Curto and F. Simini. CINARTRO: Measurement of quadriceps moment arm to assess knee kinematics. In 22nd Congress of the European Society of Biomechanics. 2016; 10-15.

20. F. Simini, D. Santos and L. Francescoli. Videofluoroscopy instrument to identify the tibiofemoral contact point migration for anterior cruciate ligament reconstruction follow-up: CINARTRO. J. Phys. Conf. Ser. 2016; 705. | Article

21. Gill HS and O'Connor JJ. Biarticulating two-dimensional computer model of the human patellofemoral joint. Clin Biomech (Bristol, Avon). 1996; 11:81-89. | Article | PubMed

22. Fantozzi S, Cappello A and Leardini A. A global method based on thinplate splines for correction of geometric distortion: an application to fluoroscopic images. Med Phys. 2003; 30:124-31. | Article | PubMed

23. D. Santos. Estudio de los Centros de Rotación Instantáneos de la Rodilla en Pacientes con Plastia del Ligamento Cruzado Anterior. Tesis de maestría en Ciencias Médicas; PROINBIO, Universidad de la República. Montevideo. 2014.

24. J. Artigas, D. Santos, P. Castrillo, V. Gigirey and F. Simini. Evaluation of Radiological Knee Landmarks Determination for Kinematics Validation of CINARTRO. In XVII Congresso Brasileiro de Biomecânica (CBB). 2017.

25. Baltzopoulos $V$. Muscular and tibiofemoral joint forces during isokinetic concentric knee extension. Clin Biomech (Bristol, Avon). 1995; 10:208214. | Article | PubMed

26. D. Santos, L. Francescoli, J. Loss, F. Arbío and F. Simini. A Tool to Assess Anterior Cruciate Ligament Recostruction by Quantitative Localization of the Knee Centre of Rotation. In 19th Congress of the European Society of Biomechanics (ESB2013). 2013.

\section{Citation:}

Simini F, Santos D, Artigas J, Gigirey V, Dibarboure L and Francescoli L. Measurement of knee articulation laxity by videofluoroscopy image analysis: CINARTRO. Med Imaging Radiol. 2017; 5:4. http://dx.doi.org/10.7243/2054-1945-5-4 